\title{
COMPARATIVE EVALUATION OF EFFICACY OF CAUDAL BUPIVACAINE ALONE OR IN COMBINATION WITH BUTORPHANOL OR CLONIDINE FOR POSTOPERATIVE ANALGESIA IN CHILDREN
}

Veena Chatrath, Sarabjit Kaur, Joginder Pal Attri, Ranjana Khetarpal, Radhe Sharan, Gurmeet Kaur

\footnotetext{
1. Professor and Head, Department of Anaesthesia, Government Medical College, Amritsar, Punjab.

2. Professor, Department of Anaesthesia, Government Medical College, Amritsar, Punjab.

3. Associate Professor, Department of Anaesthesia, Government Medical College, Amritsar, Punjab.

4. Assistant Professor, Department of Anaesthesia, Government Medical College, Amritsar, Punjab.

5. Assistant Professor, Department of Anaesthesia, Government Medical College, Amritsar, Punjab.

6. Senior Resident, Department of Anaesthesia, Government Medical College, Amritsar, Punjab.
}

\section{CORRESPONDING AUTHOR}

Dr Veena Chatrath, Prof. \& Head,

Dept. of Anaesthesia,

Govt. Medical College,

Amritsar (Punjab)-143001,

E-mail: drveenachatrath@yahoo.com,

Ph: 00919814112355.

ABSTRACT: BACKGROUND: Addition of adjuvant in caudal block along with bupivacaine prolongs the duration of postoperative analgesia. AIMS: The aim of this study was to evaluate the efficacy of caudal bupivacaine alone or in combination with butorphanol or clonidine for postoperative analgesia in children undergoing infra-umbilical surgeries. MATERIAL AND METHODS: This study was a prospective, randomized, double blind study and seventy five children of ASA grade I and II of either sex aged 3-8yr were randomized to one of the three groups. Group A received $1 \mathrm{ml} / \mathrm{kg}$ of $0.25 \%$ bupivacaine; Group B received $20 \mu \mathrm{g} / \mathrm{kg}$ of butorphanol in combination with $1 \mathrm{ml} / \mathrm{kg}$ of $0.25 \%$ bupivacaine; and Group C received $2 \mu \mathrm{g} / \mathrm{kg}$ of clonidine in combination with $1 \mathrm{ml} / \mathrm{kg}$ of $0.25 \%$ bupivacaine caudally after general anaesthesia was induced. Hemodynamic variables (HR, SpO2, RR and NIBP) were monitored in all patients. Sedation score, mean duration of analgesia, modified objective pain score and requirement of rescue analgesia were recorded at preset time intervals along with various complications like nausea, vomiting, hypotension, bradycardia, respiratory depression, retention of urine, sweating, pruritis, hallucinations. STATISTYICAL ANALYSIS: ANOVA test ( Analysis of variance) for intergroup comparison with parametric data, Student's paired t test for intragroup comparison, chi square test for non parametric data and complications and coefficient of variation for variation of parameters from the baseline. RESULTS: Mean duration of analgesia was maximum in group B $(822.0 \pm 217.41 \mathrm{~min})$ than in group A $(383.2 \pm 81.04 \mathrm{~min})$ and group C (745.4 $\pm 216.69 \mathrm{~min})$ and it was statistically significant. The longer duration of sedation observed in group $C$ was also statistically significant. No significant difference was observed in incidence of hemodynamic changes or side effects. CONCLUSION: Our results concluded that the addition of butorphanol and clonidine to bupivacaine resulted in superior analgesia with a longer duration of analgesia as compared to caudal bupivacaine alone. Moreover, addition of clonidine to bupivacaine resulted in a higher sedation score which is desirable in children.

KEYWORDS: Paediatric surgery, caudal analgesia, butorphanol, clonidine, bupivacaine. 
INTRODUCTION: Caudal epidural block is one of the most popular, reliable, and safe techniques in paediatric analgesia that can provide intra-operative and post-operative analgesia for a variety of infra- and supraumbilical surgical procedures. The main disadvantage of caudal analgesia is the short duration of action after a single injection. ${ }^{1}$ Prolongation of caudal analgesia using a 'single-shot' technique has been achieved by the addition of various adjuvants, such as epinephrine, opioids, ketamine, and $\alpha_{2}$ agonists. $^{2}$

Butorphanol is a totally synthetic compound of nalorphine cyclazocine series. It is a mixed agonist - antagonist opioid having intrinsic activity at ' $\mu$ ' type of opioid receptors and agonist at ' $\kappa$ ' receptors. Its interaction with these receptors in the central nervous system apparently mediate most of its pharmacological effects, including analgesia. It has an analgesic action similar to that of morphine but with less respiratory depression and may produce less nausea and vomiting. Its high lipid solubility and high affinity for opioid receptors are additional factors that contribute to the paucity of side effects with its use. ${ }^{3}$

Clonidine is an imidazoline derivative with $\alpha_{2}$ agonist activity. After it's administration into the subarachnoid or epidural space, clonidine provides a substantial antinociceptive effect by acting on the $\alpha_{2}$ receptors in the dorsal horn of spinal cord and brain stem nuclei implicated in pain. Clonidine has sedative property and it is often a desirable feature as it reduces the requirement of hypnotics. ${ }^{4}$

Krane conducted a study in 1987 in which caudal morphine was used with bupivacaine for caudal analgesia and it was found to prolong the duration of analgesia but with significant side effects like nausea, vomiting, pruritis, urinary retention and delayed respiratory depression.5,6 Another study compared caudal bupivacaine-clonidine mixture with plain bupivacaine and concluded that addition of clonidine to bupivacaine improve the efficacy of caudal anaesthesia along with prolonged sedation in children7. Lawhorn C D et al in 1997 added butorphanol to bupivacaine for caudal analgesia and found an increase in the duration of analgesia ${ }^{8}$.

We planned this study to compare the post-operative analgesic effects and side-effects of caudal bupivacaine alone or in combination with butorphanol or clonidine for caudal analgesia in children undergoing infra-umbilical surgeries.

MATERIAL AND METHODS: After obtaining approval from hospital ethical committee, and taking written informed consent from parents, we included 75 patients of ASA I and II aged 3-8 years in this prospective randomized double blind study. The children were scheduled for elective infraumbilical surgeries under caudal block. The study were conducted in a duration of 2 years.

Exclusion criteria included refusal by the parents, presence of a significant sacral deformity, infection of the skin or subcutaneous tissue in the puncture area, coagulation defects, demyelinating disease of the CNS, hypersensitivity to local anaesthetics, severe hypovolemia, mental retardation and history of convulsions. Patients were randomly assigned to one of three groups by computerised random number by an investigator with no clinical involvement in the trial. Blinding was used to avoid patient selection bias. The anaesthesiologist giving the caudal block as well as the observer who monitored the post-operative analgesia were both blinded to the study drug. Using computer generated random numbers patients were allocated into three groups of 25 each. Group A patients received $1 \mathrm{ml} / \mathrm{kg}$ of $0.25 \%$ bupivacaine with $0.1 \mathrm{ml} / \mathrm{kg}$ normal saline as control. Group B patients received $1 \mathrm{ml} / \mathrm{kg}$ of $0.25 \%$ bupivacaine and butorphanol $20 \mu \mathrm{g} / \mathrm{kg}$. Group C patients received $1 \mathrm{ml} / \mathrm{kg} 0.25 \%$ bupivacaine and clonidine 2 
$\mu \mathrm{g} / \mathrm{kg}$. Drug solutions were prepared by an anaesthesiologist who was blinded to the nature of the study. For each patient two different syringes were prepared. One syringe contained bupivacaine and the other contained either $0.1 \mathrm{ml} / \mathrm{kg}$ of normal saline or clonidine or butorphanol. Normal saline was added to clonidine or butorphanol to achieve a total volume of $0.1 \mathrm{ml} / \mathrm{kg}$. Volume of the drug solutions was kept constant in all the three groups.

Detailed preanaesthetic check up of the children was done a day prior to surgery and the children were kept fasting for 4-6 hrs. On the day of surgery, the children were reassessed in the preanaesthetic room. Premedication was given orally with syrup promethazine $1 \mathrm{mg} / \mathrm{kg} 45$ minutes before surgery.

In the operating room, precordial stethoscope and monitor to check for heart rate, respiratory rate, non invasive blood pressure and Sp02 were attached and the baseline parameters were recorded. The children were induced with oxygen, nitrous oxide (50:50) and halothane with appropriate size of face mask and Jackson-Ree's circuit. Intravenous line was started and intravenous fluids were given according to the body weight of the child. Operative procedures performed were circumcision, herniotomy, hypospadias, orchidopexy etc.

After adequate level of anaesthesia caudal block procedure was performed with short bevelled $22 \mathrm{G}$ needle. Identification of the space was done with whoosh test. A mechanical stimulus was applied at the surgical dermatome or at the immediate superior dermatome with a modified Alis clamp for the evaluation of block onset. Surgery was started 15 minutes after the caudal block when there was no limb movement to the mechanical stimulus. Surgery was allowed only after an adequate effect was achieved. Caudal effectiveness score was assessed

\section{Table - 1 Caudal effectiveness score}

\begin{tabular}{|c|c|}
\hline Score & Definition \\
\hline 0. & Impossible to reduce halothane concentration at any time during surgery. \\
\hline 1. & Halothane concentration increased after initial reduction. \\
\hline 2. & $\begin{array}{l}\text { Halothane concentration reduced; heart rate or blood pressure increase } \geq 20 \% \\
\text { of the baseline. }\end{array}$ \\
\hline 3. & $\begin{array}{l}\text { Halothane concentration reduced; heart rate and blood pressure increase }< \\
20 \% \text { of baseline. }\end{array}$ \\
\hline
\end{tabular}

Patients were monitored intraoperatively for heart rate, respiratory rate, blood pressure, oxygen saturation after every 5 min interval during the surgery. Postoperatively in the recovery room these parameters were monitored for $2 \mathrm{hrs}$ at the interval of $15 \mathrm{~min}$ and in the ward 2 hourly for six hours and then at 12 and 24 hrs.

Postoperatively sedation and severity of pain was assessed using sedation score ${ }^{9}$ (table 2 ) and modified objective pain score ${ }^{10}$ (OPS) (table 3) respectively. 


\section{Table 2- Sedation score}

\begin{tabular}{|c|l|}
\hline Grade & \multicolumn{1}{|c|}{ Definition } \\
\hline 0 & Fully awake \\
\hline 1 & Slightly drowsy \\
\hline 2 & Asleep but easily arousable \\
\hline 3 & Fully asleep but arousable \\
\hline 4 & Fully asleep but not arousable \\
\hline
\end{tabular}

Table 3- Modified Objective pain score

\begin{tabular}{|l|l|l|l|}
\hline \multicolumn{1}{|c|}{ VARIABLE } & \multicolumn{1}{|c|}{ SCORE 0 } & \multicolumn{1}{c|}{ SCORE 1 } & \multicolumn{1}{c|}{ SCORE 2 } \\
\hline Crying & None & Consolable & Not consolable \\
\hline Movement & None & Restless & Thrashing \\
\hline Agitation & Asleep/Calm & Mild & Hysterical \\
\hline Posture & Normal & Flexed & Holds injury site \\
\hline Verbal & Asleep/No complaint & $\begin{array}{l}\text { Complains but } \\
\text { cannot localize }\end{array}$ & $\begin{array}{l}\text { Complains and can } \\
\text { localize }\end{array}$ \\
\hline
\end{tabular}

Side effects including nausea, vomiting, hypotension, bradycardia, respiratory depression, retention of urine, sweating, flushing, pruritis, hallucination or any other side effect was noted.

Rescue analgesia was given with oral paracetamol $20 \mathrm{mg} / \mathrm{kg}$ to the children when the modified objective pain score was $\geq 4$. The number of rescue analgesic doses and total requirement of analgesic doses was noted in the postoperative period.

STATISTICAL ANALYSIS: At the end of this study, decoding of the drug solutions was done and the results were analysed statistically using ANOVA test for intergroup comparison and student's $\mathrm{T}$ test for intragroup comparisons. Chi-square test was performed to analyse nonparametric data.

RESULTS: The age, sex, weight, ASA status and duration of surgery of the patients were comparable in the three groups and there was no statistical difference in between them (Table4). Caudal effectiveness score was assessed in all the patients and no significant difference was found in between the three groups. 
Table 4- Showing demographic Data and duration of surgery among various groups

\begin{tabular}{|l|l|l|l|l|}
\hline Group & A & B & C & P value \\
\hline Age (yr) & $4.56 \pm 1.82$ & $4.6 \pm 1.75$ & $5.08 \pm 1.55$ & $>0.05$ \\
\hline Sex (Male : Female) & $20: 5$ & $22: 3$ & $21: 4$ & $>0.05$ \\
\hline Weight (kg) & $15.8 \pm 3.4$ & $16.12 \pm 3.95$ & $16.88 \pm 2.71$ & $>0.05$ \\
\hline Duration of Surgery (min) & $30.40 \pm 12.82$ & $31.00 \pm 11.99$ & $38.60 \pm 18.51$ & $>0.05$ \\
\hline
\end{tabular}

In the postoperative period urinary retention was noted in all the groups and nausea was seen in group A \& B but the difference was not statistically significant. No patient had respiratory depression, pruritis, hallucinations, sweating/ flushing, laryngospasm, hypotension and cardiac event.

Table 5- Showing Sedation score, Mean duration of analgesia, Mean dose of rescue analgesia \& OPS

\begin{tabular}{|l|l|l|l|}
\hline Group & $\mathrm{A}$ & B & C \\
\hline Sedation score & $1.48 \pm 0.71$ & $2.08 \pm 0.70^{*}$ & $2.36 \pm 0.70^{*}$ \\
\hline $\begin{array}{l}\text { Mean duration of analgesia } \\
\text { (min) }\end{array}$ & $383.2 \pm 81.04$ & $822.0 \pm 217.41^{*}$ & $745.4 \pm 216.69^{*}$ \\
\hline Mean dose of rescue analgesia & $1.96 \pm 0.61$ & $0.80 \pm 0.41^{*}$ & $0.96 \pm 0.45^{*}$ \\
\hline Objective Pain Score (OPS) & $3.44 \pm 0.91$ & $2.52 \pm 0.65^{*}$ & $2.28 \pm 0.84^{*}$ \\
\hline
\end{tabular}

The sedation score was maximum at ' 0 ' minute in the recovery room. i.e. $1.48 \pm 0.71$, $2.08 \pm 0.70$ and $2.36 \pm 0.70$ in Group A, B and C respectively and after that it gradually diminished so that at $90 \mathrm{~min}$., it was $0.40 \pm 0.50,0.84 \pm 0.55$ and $1.32 \pm 0.55$ in the three groups respectively. After 90 min the patients in Group A were fully conscious. The sedation score of the patients in groups B was $0.52 \pm 0.51$ up to $4 \mathrm{hrs}$ in the ward and in group $C$ the sedation score was $0.52 \pm 0.43$ up to $6 \mathrm{hrs}$ in the ward. The comparison of sedation score between Group A, B and C was statistically significant in the recovery room and in the ward ( $p$ value $<0.05$, paired t test. (Table $5)$.

The mean duration of analgesia was statistically longer ( $\mathrm{p}$ value $<0.01$ ) in the group $B$ $(822.0 \pm 217.41 \mathrm{~min})$ and group $\mathrm{C}(745.4 \pm 216.69 \mathrm{~min})$ than group A $(383.2 \pm 81.04 \mathrm{~min})$. The total number of 'rescue' analgesic doses required in the first 24 hrs was lesser in group B ( $0.80 \pm$ $0.41)$ than both groups A $(1.96 \pm 0.61)$ and C $(0.96 \pm 0.45)$ (Table 5).

The objective pain score was less in group B and C compared to group A. The OPS was again statistically significant in comparing group A \& B and A \& C throughout the postoperative period ( $\mathrm{p}$ value $<0.05$, paired $\mathrm{T}$ test). But OPS score was not statistically significant between Group B and C.(Table 5).

DISCUSSION: Surgical procedures in children are followed by pain which may give rise to restlessness, tachycardia, fear, crying, anxiety and agitation in children. To negate this 
physiological and psychological effects of pain and to improve the quality of analgesia, caudal epidural block is a well known method.11

Caudal block is easy to perform and has been found to be very effective in children. Caudal anaesthesia is the most frequently used regional technique in children, accounting for almost $50 \%$ of all regional techniques. When caudal block is used as a supplement to general anaesthesia in children, it decreases the intra-operative requirement for general anaesthesia, with lesser use of parenteral opioids thereby limiting the incidence of respiratory depression and it also limits the stress hormone response. ${ }^{11}$ Many anaesthetic agents have been used for caudal analgesia in paediatric patients, with bupivacaine and lignocaine being most common.

Bupivacaine when used alone through caudal route has the limitation of short duration of action. Different additives have been used to prolong the duration of analgesia even with longer acting local anaesthetics. To prolong the duration of single shot caudal analgesia and to decrease the individual dose of the drugs, many adjuvants have been administered along with bupivacaine eg. Morphine, clonidine, tramadol, ketamine, neostigmine and butorphanol. ${ }^{12,13}$

Butorphanol is a mixed agonist - antagonist with intrinsic activity at receptors of the mu opioid type (morphine like). It is also an agonist at kappa opioid receptors. Its interactions with these receptors in the CNS apparently mediate most of its pharmacological effects, including analgesia. Butorphanol has an analgesic action similar to that of morphine, with less respiratory depression, less nausea and vomiting, no undesirable psychomimetic effects. ${ }^{14}$

Clonidine an $\alpha_{2}$ agonist has also been used as additive to local anaesthetics. It's addition increases duration and improves quality of analgesia provided by single shot caudal anaesthesia. Clonidine when used extradurally provides analgesia by nonopioid spinal effects.

The present study was conducted to compare the analgesic efficacy of caudal bupivacaine alone or in combination with butorphanol or clonidine for post-operative analgesia. The demographic profile of our patients was comparable with respect of age, sex, body weight, ASA status and duration of surgery. The results of our study have shown that caudal administration of bupivacaine with the addition of $20 \mu \mathrm{g} / \mathrm{kg}$ butorphanol and $2 \mu \mathrm{g} / \mathrm{kg}$ clonidine resulted in significant increase in analgesia time than bupivacaine alone. The mean duration of post-operative analgesia was $383.2 \pm 81.04 \mathrm{~min}$ in bupivacaine group, $822.0 \pm 217.41 \mathrm{~min}$ in butorphanol group and $745 \pm 216.69 \mathrm{~min}$ in clonidine group. The prolongation of duration of analgesia was significant in both butorphanol and clonidine group when compared to bupivacaine alone group. The findings of our study were consistent with the studies conducted by others. $.7,8$.

Sedation may be beneficial especially in paediatric population. Children who sleep for many hours after surgery are perceived more comfortable by the attending nurses and families. Also it offers advantages in children who would benefit from sedation in order to tolerate any necessary monitors, lines or drains postoperatively. In a previous study by Bailey et al, the incidence of sedation was significantly higher in paediatric patients receiving caudal butorphanol. 15

In our study also we found that sedation score was significantly higher in Group C (clonidine $2 \mu \mathrm{g} / \mathrm{kg}$ with $0.25 \%$ bupivacaine $1 \mathrm{ml} / \mathrm{kg}$ ) compared to Group A and Group B. The findings of our study are consistent with the findings of Lee $\mathrm{JJ}$ et al who found significant sedation with clonidine in the doses of $2 \mu \mathrm{g} / \mathrm{kg} .{ }^{9}$

In our study Modified Objective Pain Score (OPS) was used to evaluate the pain in children and gives an objective evaluation of pain. None of the patients had pain in the recovery room i.e. for up to 2 hours postoperatively and hence none of the patients required any rescue 
analgesia during this period. In the ward OPS started increasing at $4 \mathrm{hrs}$ in Group A and at $6 \mathrm{hrs}$ in Group B and C. After that OPS started falling till the end of observation period. This can be contributed to the fact that most of the patients received the rescue analgesia during this period. Singh V et al concluded that need for rescue analgesia in PACU and total numbers of doses of morphine administered were significantly less in patients in whom butorphanol was added to bupivacaine in caudal epidural analgesia. ${ }^{8}$

In our study, the variation in the heart rate, blood pressure, respiratory rate and $\mathrm{SpO}_{2}$ was comparable in all the three groups in both the intraoperative and the postoperative periods and this was not statistically significant. This implies that addition of butorphanol/clonidine to bupivacaine did not produce any significant effect on haemodynamics.8,9

Martin et al carried out a study and found that with caudal anaesthesia the most common side effect is urinary retention. ${ }^{15}$ In our study 4\% patients in Group A, 8\% patients in Group B and 4\% patients in Group C had urinary retention. In a previous study by Aggarwal and Taylor, no patient had pruritis and respiratory depression following caudal butorphanol. ${ }^{16}$ Similarly no patient in our study had pruritis and respiratory depression. The side effect profile of bupivacaine, butorphanol and clonidine were favourable and nonsignificant on statistical comparison among the three groups.

CONCLUSION: From the present study it is concluded that caudal administration of bupivacaine with addition of butorphanol or clonidine, is a reasonably safe and effective means for paediatric caudal analgesia in children undergoing infraumbilical surgeries to increase the duration and quality of analgesia without any haemodynamic instability and increase in side effects. Furthermore, the addition of clonidine also increased the duration of sedation, which is a desirable feature in children.

\section{Figure 1: Showing mean sedation score in the three groups at different time intervals in recovery room}

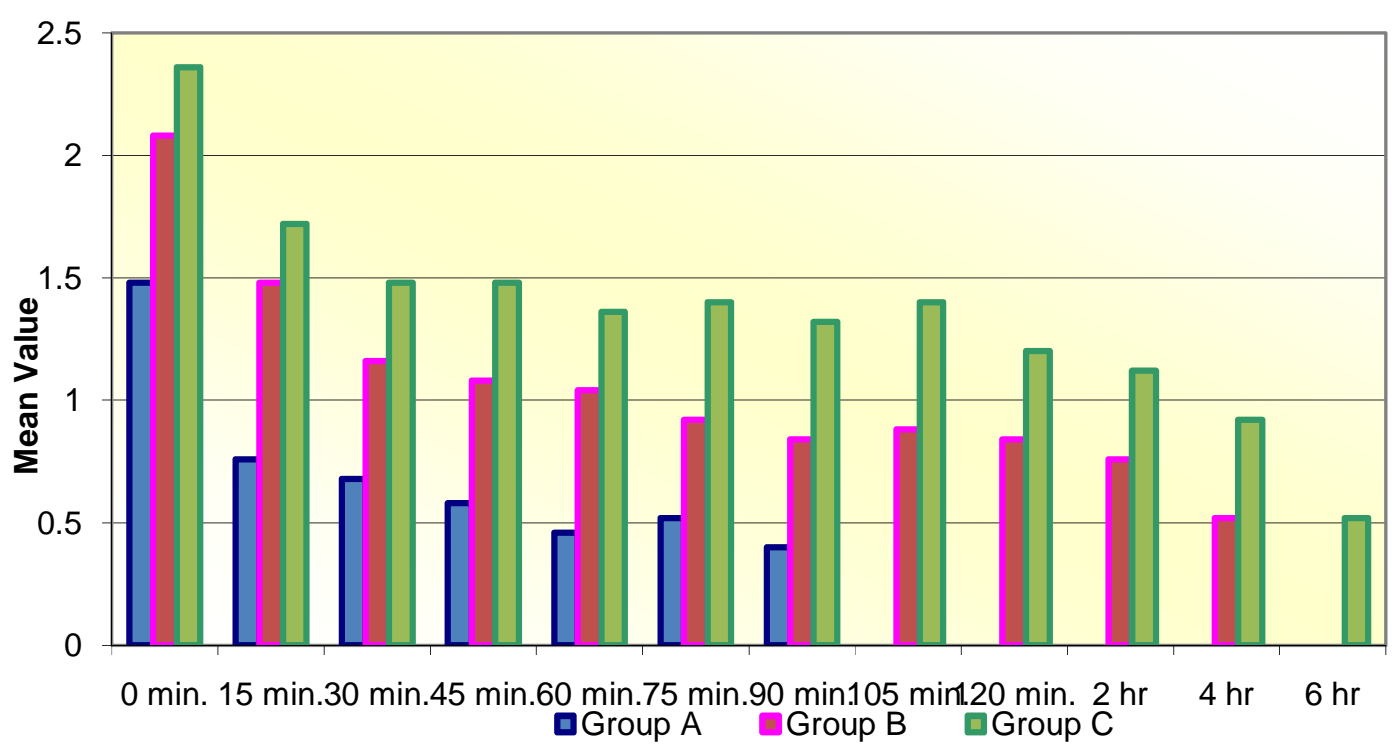


Figure 2: Showing mean ops in the three groups at different time intervals in recovery room

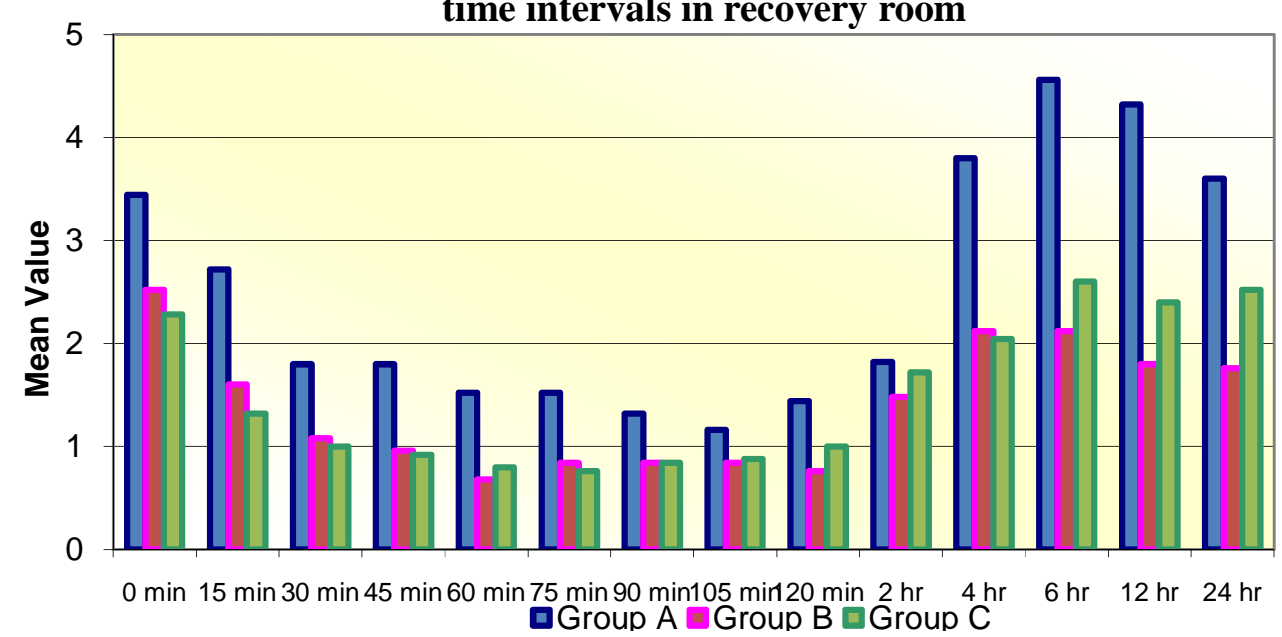

\section{REFERENCES:}

1. Lloyd-Thomas AR. Pain management in paediatric patients. Br J Anaesth 1990;64:85-104.

2. Vetter TR, Carvallo D, Johnson JL, Mazurek MS, Presson RG. A comparison of singledose caudal clonidine, morphine, or hydromorphone combined with ropivacaine in pediatric patients undergoing ureteral reimplantation. Anesth Analg 2007; 104:1356-63.

3. Sung YF, Weinstein MS, Ghani GA. Balanced anesthesia: a comparision of butorphanol and morphine. Southern Medical Journal 1984; 77:180-182.

4. Eisenach J, Detweiter D, Hood D. Haemodynamic and analgesic action of epidurally administered clonidine. Anaesthesiology 1993; 78:277-87.

5. Krane EJ. Tyler DC. Jacobson LE. The dose response of caudal morphine in children. Anaesth 1989; 71:48-52.

6. Krane EJ. Delayed respiratory depression in a child after caudal epidural morphine. Anaesth analg 1988; 67:79-82.

7. Klimscha W, Chiairi A. The efficacy and safety of clonidine/bupivacaine combination in caudal blockade for paediatric hernia repair. Anesth Analg 1998;86:54-61.

8. Lawhorn CD, Stoner JM, Schimtz ML, Brown RE, Jr. Stewart FW, Volpe P et al. Caudal epidural butorphanol plus bupivacaine versus bupivacaine in pediatric outpatient genitourinary procedures. J Clin Anesth 1997; 9:103-8.

9. Lee JJ, Rubin AP. Comparison of a bupivacaine-clonidine mixture with plain bupivacaine for caudal anaelgesia in children. Br J Anaesth 1994; 72:258-62.

10. Nordon J, Hannallah R, Geston P. Reliability of objective pain scale in children. Anesth Analg 1991; 72:99.

11. Yaster M, Maxwell LG. Pediatric regional anesthesia. Anesth 1989; 70:324-38.

12. Armitage EN, Caudal block in children. Anaesth 1979; 34:396.

13. Armitage EN, Lunn JN. Analgesia after circumcision. Anaesth 1980; 35:77-78.

14. Singh V, Kanaujia A, Singh GP. Efficacy of caudal butorphanol. In J Pediatr 2006; 73:14750 .

15. Martin L M. Penile block associated with less urinary retention than caudal anaesthesia in distal hypospadias repair in children. World J of Urology 2010;28:87-91.

16. Aggarwal R, Taylor BD. Caudal epidural butorphanol in children. Anesth Analg 1993; $76: 3$. 